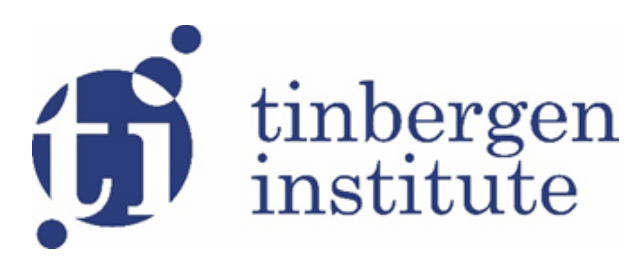

TI 2021-003/V

Tinbergen Institute Discussion Paper

\title{
Mental Health Effects of Same-Sex Marriage Legalization
}

Shuai Chen ${ }^{1}$

Jan van Ours ${ }^{2}$

${ }^{1}$ Luxembourg Institute of Socio-Economic Research

2 Erasmus University Rotterdam 
Tinbergen Institute is the graduate school and research institute in economics of Erasmus University Rotterdam, the University of Amsterdam and Vrije Universiteit Amsterdam.

Contact: discussionpapers@tinbergen.nl

More TI discussion papers can be downloaded at https://www.tinbergen.nl

Tinbergen Institute has two locations:

Tinbergen Institute Amsterdam

Gustav Mahlerplein 117

1082 MS Amsterdam

The Netherlands

Tel.: +31(0)205984580

Tinbergen Institute Rotterdam

Burg. Oudlaan 50

3062 PA Rotterdam

The Netherlands

Tel.: +31(0)10408 8900 


\title{
Mental Health Effects of Same-Sex Marriage Legalization
}

\author{
Shuai Chen* Jan C. van Ours ${ }^{\dagger}$
}

January 3, 2021

\begin{abstract}
Sexual minorities have had worse than average mental health, which may have to do with actual or perceived discrimination. Same-sex marriage legalization (SSML) is a typical anti-discrimination policy removing marital restrictions for sexual minorities. We study how this legislation affected mental health of sexual minorities in the Netherlands. Conducting a difference-in-differences analysis, we compare changes in mental health following the legalization between sexual minorities and heterosexuals. We find that SSML improved mental health of both married and non-married sexual minorities, which implies that marriage is not the only channel. Examinations of alternative mechanisms combined with literature suggest that the legislation may also take effect by improving societal tolerance as well as stabilizing partnerships and enriching the choice basket of partnership forms for sexual minorities.
\end{abstract}

Keywords: Same-sex marriage, Mental health, Sexual minorities JEL-codes: I12, I18, J12, J15, K36

Declarations of interest: none

This research did not receive any specific grant from funding agencies in the public, commercial, or not-for-profit sectors.

The authors are grateful to participants at an AEA Virtual Seminar on LGBTQ+ Economics, and attendants at EALE-SOLE-AASLE World Conference 2020, EEA Congress 2020 and a SOGI Economics Early Career Workshop for their helpful comments and suggestions on a previous version of this paper. The authors thank Statistics Netherlands (CBS) for making their restricted access micro-data available for analysis through a remote access facility.

\footnotetext{
${ }^{*}$ Luxembourg Institute of Socio-Economic Research (LISER), Luxembourg; email: shuai.chen@liser.lu

${ }^{\dagger}$ Erasmus School of Economics, Rotterdam, the Netherlands; Department of Economics, University of Melbourne, Australia; Tinbergen Institute (Rotterdam), CEPR (London) and IZA (Bonn); email: vanours@ese.eur.nl.
} 


\section{Introduction}

According to recent estimates, in 2017 worldwide 971 million people suffered from mental health issues (GBD 2017 Disease and Injury Incidence and Prevalence Collaborators, 2018). Among them, 264 million had depression (of which 163 million cases were major ones) and 284 million had anxiety disorders. Such mental health problems exhibit for both genders and across all age groups with substantial differences in causes, locations and so on. Mental disorders may cause important adverse individual economic performances including reducing employment and thus income (see Ridley et al. (2020) for an overview of the recent work on the economics of mental health). Our study focuses on mental health divergence in sexual orientation that may be attributed to either actual or perceived discrimination against sexual minorities.

Although the extent of discrimination against sexual minorities is varying across countries and regions, there is no doubt about the existence of this type of discrimination. In addition to discrimination in the labor market (Ahmed et al., 2013; Plug et al., 2014; Bertrand and Duflo, 2017; Coffman et al., 2017; Neumark, 2018; Sansone, 2019), sexual minorities have been confronted with other kinds of discrimination such as that in housing (Badgett et al., 2020). For a long time, homosexuality was considered to be a disease rather than a way of life. The World Health Organization, for example, published the International Statistical Classification of Diseases and Related Health Problems (ICD) in 1948 in which homosexuality was classified as a mental disorder. ${ }^{1}$ Same-sex relationships were against the law in many countries in the past, and they still are in some countries nowadays. Due to such discrimination and unfair treatment, sexual minorities may have suffered more from mental health problems than heterosexuals.

However, opinions about same-sex relationships have been gradually evolving. As part of structural changes in partnership formations and family institutions, countries around the world have started to accept and formalize same-sex relationships to the extent that some of them even legalized same-sex marriages. ${ }^{2}$ Same-sex marriage legalization (SSML) is a typical anti-discrimination policy removing marital restrictions for sexual minorities and thus providing them with marriage equality. Such marital policy reform may help to mitigate mental health issues of sexual minorities to some extent.

\footnotetext{
${ }^{1}$ It was until the 1970 s that homosexuality was not removed from the ICD; see www.who.int/news room/spotlight/international - classification - of - diseases.

${ }^{2}$ Stevenson and Wolfers (2007) provide an overview of developments of family institutions over the past decades; Ciscato et al. (2020) discuss assortative mating of same-sex couples; Baranov et al. (2020) argue that preferences for partnership formations including same-sex marriage are very persistent over time. Dee (2008) provides an early overview of same-sex partnership laws in Europe.
} 
The current study aims to establish whether SSML indeed improved mental health of sexual minorities and hence shrank the sexual orientation gap in mental health. Specifically, we exploit the 2001 same-sex marriage legalization in the Netherlands as a natural experiment to compare corresponding changes in mental health between sexual minorities and heterosexuals. Following the literature (see Ridley et al. (2020) for the recent overview), we focus on depression and anxiety - two common mental illnesses. In our analysis we use rich administrative micro-data combined with elaborate health surveys from Statistics Netherlands. With precise registered information on individual characteristics and household compositions over a relatively long period 1995-2018, we are able to accurately identify sexual minorities compared to studies based on surveys only (Raifman et al., 2017; Carpenter et al., 2018). Identification of sexual minorities comes from gender comparison between partners in (recorded) cohabiting couples as well as married couples. Correct classification between sexual minorities and heterosexuals is key to our identification strategy.

We apply a difference-in-differences (DiD) framework to examine the effects of SSML on depression and anxiety of sexual minorities. The treatment group consists of individuals who had at least one same-sex relationship during the period that the administrative micro-data cover. The control group comprises those that formed households with only different-sex partner(s). ${ }^{3}$

We find that before SSML, sexual minorities suffered more serious mental health issues than heterosexuals on average. However, SSML significantly ameliorated their mental health status. Both depression and anxiety of sexual minorities declined and converged to those of heterosexual individuals. We examine and discuss various mechanisms of marriage, marital stability, enriched choice basket of partnership forms and societal attitude change for the mental health effects of SSML. Comparing married and non-married sexual minorities post-SSML, we find that marriage was associated with significantly larger mental health gains for depression but not for anxiety. Also the beneficial mental health effects for non-married sexual minorities cannot be explained by marriage, so the legalization did not take effect through marriage only. Moreover, the legislation stabilized same-sex formal partnerships and enlarged the choice set of same-sex partnership forms, which may contribute to the mental health gains of sexual minorities. Additionally, other indirect channels such as the improvement in societal attitudes to sexual minorities (Ak-

\footnotetext{
${ }^{3}$ The main identifying assumption of our design is that SSML did not significantly deteriorate mental health of the control group, i.e. heterosexuals. If SSML instead improved mental health of heterosexuals too, then our results would be underestimated and hence become the lower bound of the true effects. Later on, we show that the legalization did not exert significant influence on mental health of heterosexuals.
} 
soy et al., 2020) and self-perception of being socially accepted (Badgett, 2011) probably play an important role. We also investigate heterogeneity of the mental health effects of SSML in terms of gender, urban characteristics of the resident place, age cohort, employment status and educational attainment. We conclude that SSML closed the sexual orientation gap of mental health more completely among women, residents in low urban regions, younger people and college degree holders.

The current study speaks to several strands of relevant literature. Principally, it adds to the small but growing academic discussion on the relationship between recognition of same-sex marriage-like partnership and health or health related behavior. Dee (2008) uses country-level panel data from Europe finding that legal recognition of same-sex marriage-like partnership statistically diminished sexually transmitted infections such as syphilis but not non-sexually transmitted ones. Hatzenbuehler et al. (2010) exploit bans of SSM in some states of the U.S. in 2004 and 2005 to examine changes in psychiatric disorders among adults. With a longitudinal data set, they provide evidence that after the bans, sexual minorities suffered a higher level of psychiatric morbidity. Hatzenbuehler et al. (2012) compare medical care visits, mental health care visits and mental health care costs among around 1,200 sexual minority male patients in Massachusetts one year before and one year after the legalization of SSM in this state. They find significant reductions in these visits and costs regardless of partnership status. Raifman et al. (2017) exploit variations in SSML across states and time and obtain an association between state SSM policies and a decrease in the rate of suicide attempts among sexual minority high school students. Carpenter et al. (2018) apply a similar design providing evidence that access to SSM raised marriage take-up among individuals living with a same-sex housemate. Access to SSM was also associated with significant increases in health care and insurance usage as well as gay men health. Somewhat less related is Francis and Mialon (2010) who conclude on the basis of an analysis of state-level panel data that tolerance for sexual minorities reduced the HIV rate. The authors identify the entry of low-risk men into same-sex partnership markets and the diminution in underground and risky behaviors of sexually active men as mechanisms. Our study contributes to this literature with our improved identification of sexual minorities, which is vital in this literature, thanks to the information on changes in the household composition in our long-period administrative micro-data. Furthermore, with a rich set of questions on mental health as well as other health indicators or health related behaviors, we are able to investigate various health dimensions.

Moreover, our paper is part of the literature on the positive association between 
formal partnerships and mental health. Chen and van Ours (2018) provide a recent overview of studies on partnership formations and subjective well-being. Based on an analysis of Dutch data the authors find that being in a formal partnership improves well-being irrespective of sexual orientation of the partners involved. Wight et al. (2013) document a similar finding about nonspecific psychological distress in California. In the current study, we find that marriage as a mechanism only partially explains the beneficial effects of SSML on mental health. Other channels including the improvement in societal attitudes toward sexual minorities as well as the increased same-sex partnership stability and the enlarged choice set of partnership forms may also be of importance. Our main finding that SSML substantially shrank the mental health gap between sexual minorities and heterosexuals is in line with that of Delhommer and Hamermesh (2020) who argue that same-sex couples benefit financially from living under the institution of legalized marriage. They attribute this gain to the couple's increased incentives to invest in their relationship under the greater legal protection of the relationship.

Last but not least, this study is closely related to research on the impacts of antidiscrimination policies. Boeri and van Ours (2013) provide an introduction of antidiscrimination legislation and an overview of studies about it. For instance, some countries aim to reduce the gender wage gap by imposing legal requirements for pay transparency. Bennedsen et al. (2020) implement a DiD analysis on the effect of such law in Denmark valid from 2006 onward for firms with over 35 workers. They document an around $7 \%$ decrease in the gender wage gap. Similarly and more prominently, Baker et al. (2019) find that this legislation in Canada on university faculty salaries reduced the gender pay gap by about $30 \%$. Another type of anti-discrimination polices is relevant to anonymity in recruitment. With a field experiment on "blind" auditions at American orchestras, Goldin and Rouse (2000) find that the partly "blind" selection process increased the probability of being recruited for women musicians. Nevertheless, Behaghel et al. (2015) document negative influence of anonymous CV's on probabilities of interview invitations and hiring for minority groups, which was contrary to the intention of the $\mathrm{CV}$ anonymity. SSML works as an anti-discrimination policy by removing or preventing steps that disadvantage minorities, which differs from affirmative action policies that require pro-active steps (Holzer and Neumark, 2000). We contribute to this literature by investigating the impact of a typical anti-discrimination policy on well-being of discriminated minorities, through the specific lens of removing discrimination against sexual minorities in the marriage market and examining the corresponding changes in their mental health. The results in our study may provide implications for anti-discrimination policies 
in general.

The remainder of the paper is organized as follows. In section 2 we compare common mental health issues - depression and anxiety - between sexual minorities and heterosexuals in the Netherlands. We then provide background information about the evolution of attitudes to sexual minorities in Europe and in particular the Netherlands. We also discuss two vital reforms of marital policies in the Netherlands, i.e. the implementation of register partnership (RP) and the legalization of same-sex marriage. Section 3 describes our data, and elaborates the information we have about mental health and how we identify sexual orientation of individuals. Section 4 explains our empirical strategy. In section 5 we present and interpret our empirical findings. Section 6 concludes.

\section{Institutional Background}

In this section, we present mental health divergence between sexual minorities and heterosexuals with an external Dutch study in psychiatry and public health. Then we compare attitudes to homosexuality among European countries suggesting that the Netherlands is an open-minded and tolerant society for sexual minorities. Furthermore, we provide a concise description of recent developments of formal partnerships relevant to sexual minorities, namely registered partnerships and same-sex marriages.

\subsection{Mental Health}

Mood disorders with major depression as the most important one and anxiety disorders are the most common mental health problems. Table 1 compares these main mental illnesses between sexual minorities and heterosexuals in the Netherlands based on the NEMESIS-2 study (Sandfort et al., 2014). The survey investigates the lifetime prevalence and the 12-month prevalence of mental disorders with a nationally representative sample in 2007-2009 for the Dutch population aged 18-64 that was sufficiently fluent in Dutch.

Sexual orientation is established in two ways in the study, based on sexual behavior and based on sexual attraction. For the former, the question is whether the respondent had sex with someone of the same sex - exclusively or not - or of the different sex; for the latter, there are five alternative answers to the question regarding sexual attraction: to women only, to men only, and three gradations of attraction to both women and men (equally, or predominantly attracted to either women or men). Respondents were classified as same-sex group if they were exclusively or predominantly attracted to someone of 
Table 1: Mental disorders in the Netherlands by sexual orientation (18-64 years old)

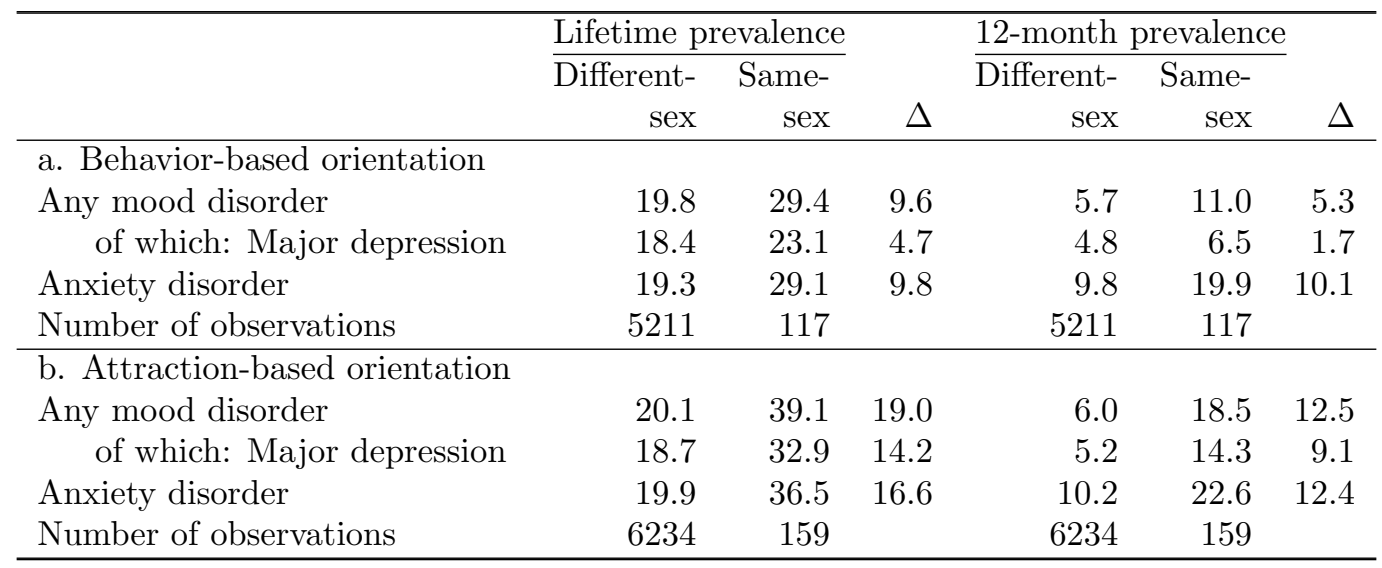

Source: Sandfort et al. (2014)

the same sex and were classified as heterosexuals otherwise.

In panel a of Table 1 with the behavior-based sexual orientation, the lifetime prevalence of major depression is 18.4 percent for heterosexuals and 23.1 percent for sexual minorities. The sexual orientation gap of major depression is hence 4.7 percentage points. Similarly, the counterpart gap for the 12-month prevalence is 1.7 percentage points. Likewise, for anxiety disorders, the sexual orientation gaps are larger - 9.8 percentage points for the lifetime prevalence and 10.1 percentage points for the 12-month prevalence. In panel b, such differences in sexual orientation measured with sexual attraction become even more substantial than the counterparts in panel a.

Irrespective of how sexual orientation is identified, mental health problems more frequently occur among sexual minorities. They have higher prevalence of major depression and anxiety disorders than heterosexual individuals. Sexual orientation is a risk factor for mental illnesses.

\subsection{Attitudes to Sexual Minorities}

The Netherlands is highly tolerant for sexual minorities as can be derived from Table 2 which provides an overview of attitudes to homosexuality in European countries. Clearly, attitudes have become more favorable in all countries presented. The percentage of the population that thought "homosexuality is never justified" dropped, for example, in Spain from a high 57 in 1981 to 17 in 2008. In Belgium, France and Norway, the other countries scoring at least $50 \%$ in 1981 on the "homosexuality never justified" question, 
the proportions were all below $20 \%$ in 2008. In the Netherlands, already in 1981 only $25 \%$ thought that homosexuality was never justified; this value further dropped to $7 \%$ in 1999. The right-hand side of Table 2 displays a similar trend of attitudes to sexual minorities in the first decade of this century in Europe with another survey question. In 2002, the share of the population that believed "gay men and lesbians should be free to live their life as they wish" was $80 \%$ or more in Belgium, Denmark, the Netherlands and Sweden. In 2010, at least $90 \%$ of the population held such opinion in Denmark, the Netherlands and Sweden.

Table 2: Attitudes to homosexuality in European countries

\begin{tabular}{lcccccc}
\hline & \multicolumn{3}{l}{$\begin{array}{l}\text { Homosexuality } \\
\text { never justified }\end{array}$} & \multicolumn{3}{c}{$\begin{array}{l}\text { Gays \& lesbians } \\
\text { live their life }\end{array}$} \\
& 1981 & 1990 & 1999 & 2008 & 2002 & 2010 \\
\hline Belgium & 52 & 41 & 27 & 16 & 80 & 87 \\
Denmark & 38 & 36 & 21 & 12 & 89 & 90 \\
France & 52 & 40 & 23 & 19 & 79 & 83 \\
Germany & 45 & 36 & 19 & 17 & 75 & 83 \\
Great Britain & 47 & 40 & 25 & 23 & 76 & 85 \\
\hline Netherlands & 25 & 13 & 7 & 8 & 88 & 93 \\
\hline Norway & 50 & 45 & - & 12 & 76 & 84 \\
Spain & 57 & 47 & 22 & 17 & 72 & 82 \\
Sweden & 39 & 37 & 9 & 12 & 82 & 90 \\
\hline
\end{tabular}

Source: Kuyper et al. (2013).

Note: The numbers are from the European Value Survey 1981, 1990, 1999, 2008 (Percentage of inhabitants thinking that homosexuality is never justified) and the European Social Survey 2002, 2010 (Percentage of population who believe that gay men and lesbians should be free to live their life as they wish).

In an open-minded society and free atmosphere as in the Netherlands, compared to other countries, one would expect the mental health effects of SSML to be limited. Thus one may regard the effects we estimate and discuss later on as a lower bound of the effects in other less tolerant or more conservative societies.

\subsection{Developments of Same-Sex Formal Partnerships}

As in many other countries, the Netherlands has experienced big changes in partnership formations. In the past decades there emerged two remarkable policy reforms of marital partnerships - the introduction of a formal registered partnership (RP) as an alternative to marriage and the legalization of same-sex marriage (SSM). RP introduced on January 1st, 1998 in the Netherlands has many of the same rights and duties as marriage does 
in, for instance, tax, property and inheritance. According to Scherf (1999) RP shares the same consequences with marriage except when children are involved. In marriage, the birth of a child automatically implies that both partners are parents. In a RP, only the biological mother is a parent in the eyes of the law whereas her partner was not considered as the other parent. Since the beginning of its implementation, RP has been open to both different-sex and same-sex couples. From April 1st, 2001 to March 1st, 2009, married couples in the Netherlands were permitted to switch their marriage to a RP. This transition could be followed by a convenient and less costly divorce process without the need to go to court. Because such divorce was not always recognized abroad as a formal divorce and lacked the legal arrangements for children born during the marriage, this so called "flash divorce" procedure was abolished on March 1st, 2009.

After being approved in the Dutch parliament by the House of Representatives on September 12th, 2000 and the Senate on December 19th, 2000, on April 1st, 2001 samesex marriage was legalized (see for details Waaldijk (2001)). Since then "marriage can be contracted by two persons of different sex or of the same sex" (Article 30 of Book 1 of the Dutch Civil Code).

Figure 1 illustrates the developments from 1998 to 2018 of the annual numbers of new formal partnerships, i.e. marriage and RP, by sexual orientation and gender. The vertical axis on the left-hand side displays the scale for different-sex couples while the one on the right-hand side shows the scale for same-sex couples. The number of different-sex couples slowly declined from 90,000 in 1998 to about 72,000 in 2013 and increased again to around 82,000 in 2018. For same-sex formal relationships there are two notable peaks - one in 1998 when RP started to be available and the other in 2001 when SSM was legalized. The year 1998 witnessed the formations of 1700 new formal partnerships of lesbian women and 1300 new ones of gay men. These numbers were very much the same in 2001. Apart from the peak periods, every year there were about 2000 same-sex formal partnerships newly formed with slightly more lesbian ones.

\section{Data}

We use data from a health survey to establish mental health conditions of individuals. Through unique individual identification numbers we are able to link the health survey sample to administrative micro-data which we need to identify the sexual orientation of individuals. 
Figure 1: Annual new formal partnerships; 1998-2018

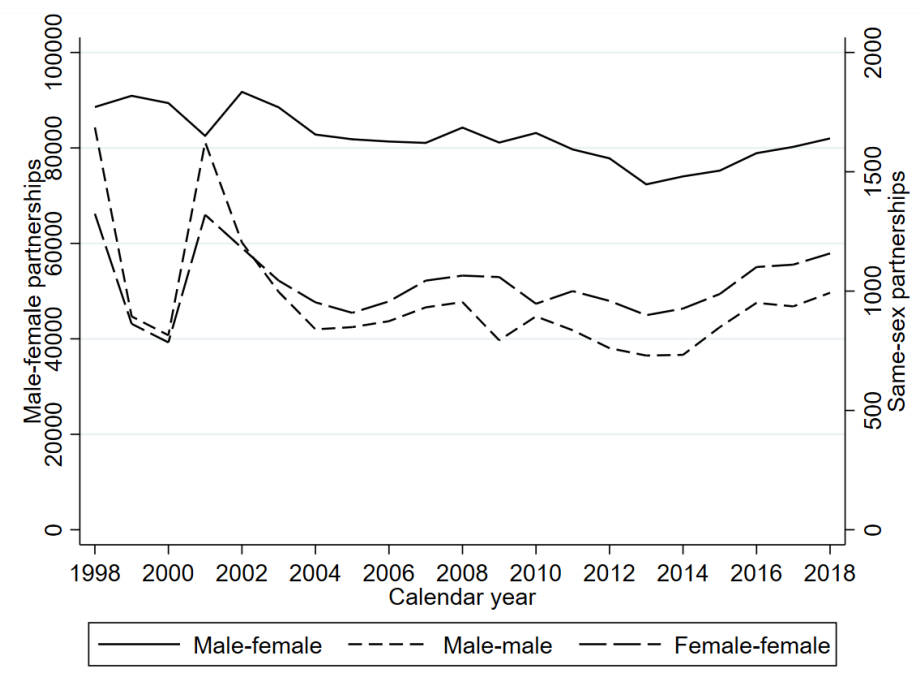

Formal partnership $=$ marriage and registered partnership. Source: Statistics Netherlands

\subsection{Sexual Orientation}

The administrative individual micro-data from Statistics Netherlands cover the whole Dutch population registered from 1995 onward. There is information about personal characteristics such as the country where the person was born, gender, immigrant status, birth year and month. Moreover, the administrative household micro-data include detailed household information over time such as the household type, change in household composition, and individual position in the household. Household types are categorized into single person, unmarried couple without children, unmarried couple with children, married couple without children, married couple with children, single parent, institutional household, and other. ${ }^{4}$ Individual positions in the household are classified into partner, single person, parent in the single parent household, children living at home, other member of the household, member of the institutional household, reference person in other household. Thus we are able to distinguish a housemate from a partner.

In order to make the assembled data available for our analysis we have to address a number of issues. First, we rely on the administrative individual and household microdata to identify same-sex and different-sex relationships by comparing the gender(s) of the two partners in a household. These relationships can be unmarried ones, i.e. (reported) cohabitation, or married ones including both RP and marriage. Second, in our study we exploit SSML in the Netherlands as a natural experiment. The treatment group

\footnotetext{
${ }^{4}$ Here marriage refers to the formal relationship including both RP and marriage.
} 
consists of individuals who had at least one same-sex relationship during the data period (1995-2018), ${ }^{5}$ and the control group is composed of individuals who formed households with only different-sex partner(s). Individuals that formed both different-sex and samesex relationships are thus included in the treatment group while people who did not report any relationship during the whole data period are excluded in our main analysis. Nevertheless, in Section 5.4 we discuss in detail how to classify these individuals with unidentified sexual orientation and conduct robustness checks corresponding to different categorizations. Third, we want to avoid potential contamination of our parameter estimates due to the impacts of the RP introduction on January 1st, 1998 and the abolition of the flash divorce on March 1st, 2009. Therefore, we discard observations before 1998 and after 2008. The estimation of the baseline model is based on a sample from 1998 to 2008. ${ }^{6}$ We drop individuals younger than 16 when they were surveyed since children may not have profound understanding on the issue of SSML. We also discard people older than 55. The reasons are threefold: first, on average sexual minorities are substantially younger than heterosexuals (see Figure 2). In the DiD setting it is preferred to compare more similar units between the treatment and control groups; second, individuals older than 55 account for a small proportion among sexual minorities; third, in labor market terms the age 55-64 is classified as old, thus we focus on the young and prime aged groups. Later on, in a sensitivity analysis with the extended sample of individuals aged 16-90 we draw the same main conclusions.

\subsection{Mental Health}

The health data are from a module of the Permanent Life Situation Study (POLS) of Statistics Netherlands. POLS is a monthly repeated cross-sectional survey starting in 1997. In every wave (month) 700-1000 individuals randomly drawn from the Dutch population answered health related questions. Starting in 2001 the survey questions on mental health changed in two aspects: phrasing and response categories. Note that the measurement changes happened from the beginning of 2001 while SSM was legalized in April of that year, so technically we can disentangle between their impacts. To connect

\footnotetext{
${ }^{5}$ Given that the legislation of SSM might encourage sexual minorities to come out of the closet and start a same-sex relationship, the assignment to treatment could be correlated with the treatment itself. That is to say, the identification of same-sex relationships could be correlated with the legalization. To alleviate this concern, in an additional sensitivity analysis we exclude from the treatment group people who started their first same-sex relationship after SSML. Our main conclusions in this sensitivity analysis are not different from the baseline analysis.

${ }^{6}$ In a separate analysis presented in Appendix B3, we investigate the mental health effects of the introduction of RP.
} 
Figure 2: Age distribution by sexual orientation

a. Heterosexuals

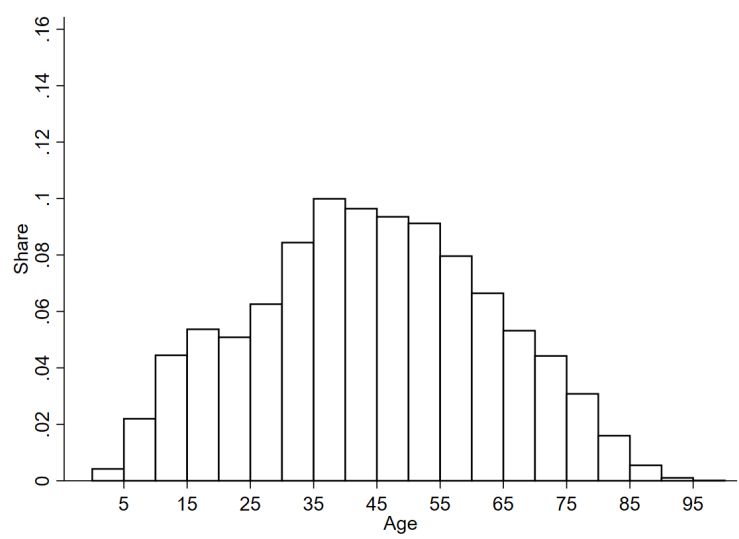

b. Sexual minorities

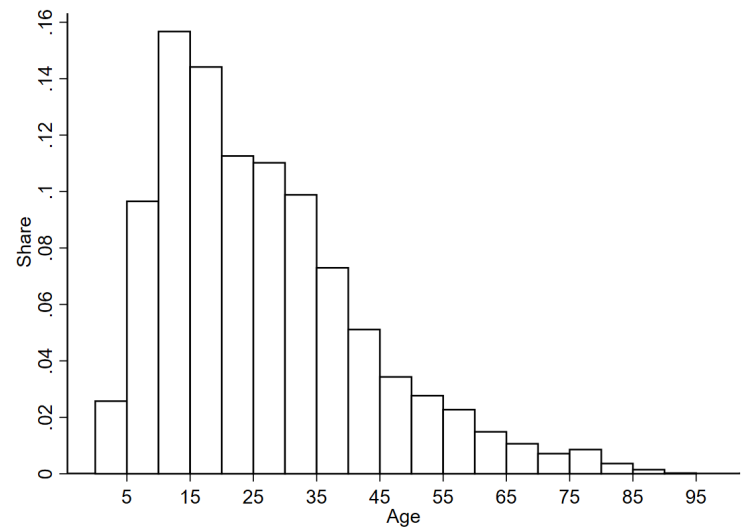

mental health variables as smoothly as possible, we re-scaled and standardized available indicators before 2001 and from 2001 onward separately. Specifically, the original responses were re-scaled to the range $[0,1]$ and then standardized to have a mean of zero and a standard deviation of one for each of the two periods. Appendix A1 provides more details on the variable transformations. ${ }^{7}$

Figure 3 illustrates the evolution of our mental health indicators over the time period 1998 to 2008. The variations in mental health consist of three components: first, calendar time variations owing to, for example, changing economic circumstances; second, the impact of the measurement change occurring at the beginning of 2001; third, the potential effect of SSML on April 1st, 2001. For heterosexuals, both depression and anxiety exhibit some mild fluctuations over time. The variations in mental health for sexual minorities present a different pattern. Before 2001, there was a huge sexual orientation gap of depression and anxiety against sexual minorities. From 2001 onward, both mental health indicators for sexual minorities declined drastically and largely converged to those of heterosexuals. If measurement change is believed to exert comparable influence on sexual minorities and heterosexuals, this figure suggests that SSML benefited the mental health of sexual minorities and considerably reduced the sexual orientation gap of mental health.

\footnotetext{
${ }^{7}$ Other outcome variables that may be related to mental health are also available, e.g. feeling nervous, general health, use of sleeping pills, feeling empty, drinking and smoking behaviors, and sexual experiences and diseases. We study them and present the results in Appendix B2.
} 
Figure 3: Developments of depression and anxiety; annual averages 1998-2008

a. Depression

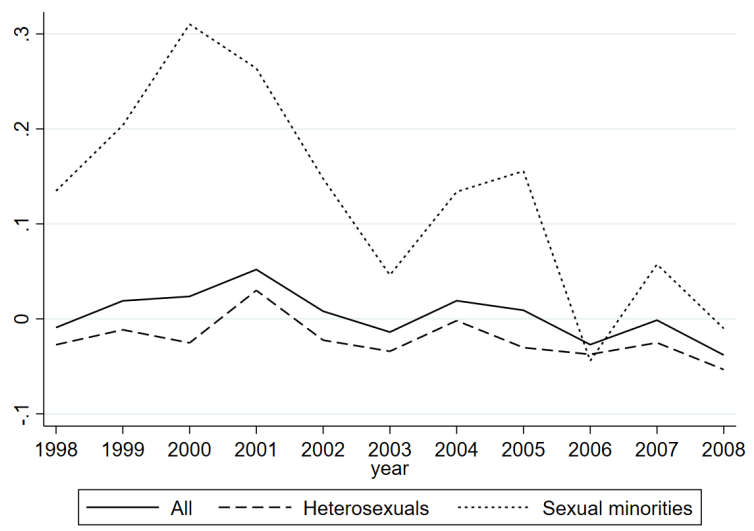

b. Anxiety

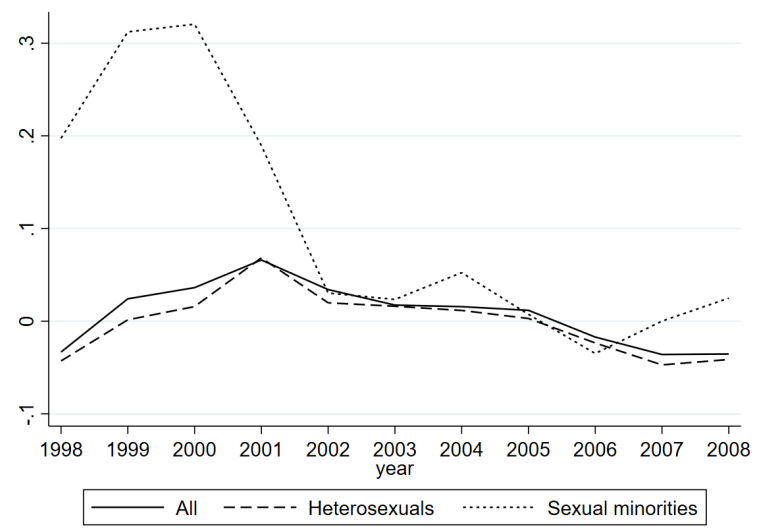

\section{Empirical Analysis}

\subsection{Exploratory Analysis}

After the data tailoring, our sample for the baseline analysis comprises 40,586 observations - 19,069 observations for males and 21,517 for females; 3,671 observations for sexual minorities and 36,915 for heterosexuals. ${ }^{8}$ The definitions and descriptives of relevant variables in the baseline model are provided in Appendix A. We consider depression and anxiety as the two main indicators of mental health. ${ }^{9}$

Table 3 reports the means of our measures of mental health by sexual orientation as well as by period, i.e. pre-SSML and post-SSML. Panel a confirms the preliminary conclusion drawn from Figure 3. On average, sexual minorities had a worse mental health status than heterosexuals. Before SSML, sexual minorities suffered 0.223 (i.e. 0.255 0.032) standard deviation higher depression than heterosexuals. A similar difference is present for anxiety. By comparing the average score in the pre-SSML and post-SSML periods for heterosexuals under the assumption that SSML did not affect their mental health, one obtains a picture how mental health varied over time because of either calendar time related developments or changes in mental health measurement. If we do the same for sexual minorities, we obtain the sum of the variations over time (including those in measurement) and the effect of SSML. Taking the difference between the changes for

\footnotetext{
${ }^{8}$ The proportion of $9 \%$ sexual minorities in our baseline sample is higher than that in other Dutch studies with representative survey samples, e.g. Buser et al. (2018) and Chen and van Ours (2018), which may imply that the excluded individuals with unknown sexual orientation (3,161 observations) are more likely to be heterosexuals. We take them into account in sensitivity analyses presented in Section 5.4.

${ }^{9}$ Both indicators have the past couple of weeks as the reference period. See also Appendix A1 for details.
} 
sexual minorities and those for heterosexuals yields the unconditional impact of SSML. The first row of panel a in Table 3 shows that for heterosexuals depression dropped by 0.059 standard deviation while for sexual minorities the decrease was 0.163 . The difference in differences suggests that SSML reduced depression for sexual minorities by 0.104 standard deviation. Likewise, the second row of panel a displays that for sexual minorities, anxiety declined by 0.237 standard deviation due to SSML.

Table 3: Mental health and marital status by sexual orientation as well as pre- and post-SSML

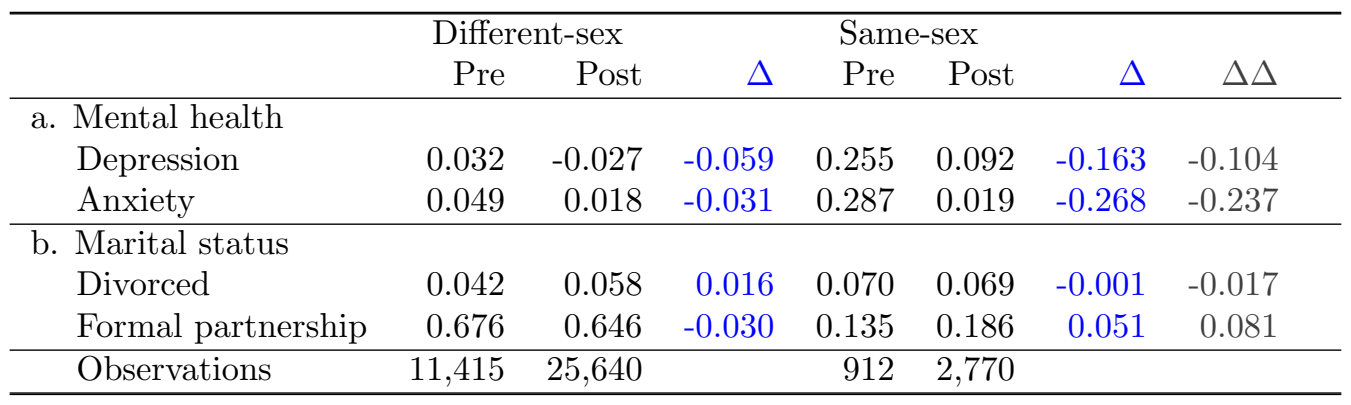

Note: Formal partnership includes both registered partnership and marriage.

\subsection{Empirical Strategy}

The calculations in Table 3 based on unconditional differences between groups suggest that sexual minorities benefited from SSML in their mental health. However, part of these differences may be attributed to heterogeneity in personal characteristics. Thus we apply a difference-in-differences (DiD) framework controlling for covariates at the individual level. We implement our main analysis with a pooled sample of men and women in which we include a dummy variable for females. Later we also examine heterogeneous effects of SSML in terms of gender, urbanization, age, labor supply and educational attainment.

The baseline model is specified as follows

$$
y_{i t m}=\alpha_{t}+\alpha_{m}+x_{i}^{\prime} \beta_{x}+\gamma_{1} S_{i}+\gamma_{2} L_{t m}+\gamma_{3} S_{i} \times L_{t m}+\epsilon_{i t m}
$$

in which $i$ denotes individuals, $t$ (1998-2008) stands for calendar years, $m(1-12)$ refers to calendar months and $y$ represents different measures of mental health, i.e. depression and anxiety. ${ }^{10}$ Furthermore, $S$ indicates a dummy for sexual minorities; $L$ is the period

\footnotetext{
${ }^{10}$ Details of specific questions about these outcome variables are in Appendix A. Moreover, the estimates for additional outcomes, such as feeling nervous, general bad health, use of sleeping pills, feeling empty, drinking and smoking behaviors, and sexual experiences and diseases, can be found in Appendix B2.
} 
of post-same sex marriage legalization, i.e. after April 1st, 2001; $x$ denotes a vector of demographic and socioeconomic covariates such as a dummy for female, the quadratic of age, dummies for marital status (married, divorced, widowed) with never married as reference, a dummy for non-Dutch nationality, a dummy for being employed, dummies for completed educational attainment (secondary school, vocational school, applied college, university) with primary school as the omitted category, and dummies for the degree of urbanization of the resident place (a little urban, medium urban, strongly urban, very strongly urban) with not urban as reference. Finally, $\alpha_{t}$ is a vector of calendar year dummies, $\alpha_{m}$ is a vector of calendar month dummies and $\epsilon$ is an error term. Note that even though measurement changes in mental health occurred in the same year as the SSML, the legislation took place in April while the measurement changes were from January onward already. Thus we are able to disentangle the effects of SSML from the impact of measurement changes by controlling for these calendar year fixed effects besides standardizing and harmonizing the indicators pre-/post-change in measurement separately.

\subsection{Parallel Trend Assumption}

In order to apply the DiD framework, the parallel trend assumption between the treatment and control groups should hold. In the current context this assumption implies that during the post-SSML period, the mental health indicators would follow the same trajectory between sexual minorities and heterosexuals in the absence of the legalization. To assess this assumption, we examine whether the pre-SSML time trends in our mental health measures diverge between sexual minorities and heterosexuals. We replace $L$ in Equation (1) by dummies for all the years separately. ${ }^{11}$ In this event study in the DiD framework, if the coefficients of interaction terms of $S$ and year dummies pre-SSML are insignificantly distinguishable from zero, it is evidence for the pre-legalization parallel trends.

Figure 4 illustrates these estimates of the interaction terms for the two mental health variables in which we normalize the coefficient of interaction of $S$ and the period 2000 to 2001 pre-law to be zero for identification. For both depression and anxiety, the estimates of the interactions of $S$ and the pre-legalization year dummies are insignificantly distinguishable from zero. Therefore, arguably, the trends measured pre-SSML between sexual

\footnotetext{
${ }^{11}$ It is called the "Auto" model following Autor (2003) or the leads and lags model by Atanasov and Black (2016).
} 
Figure 4: Event study in DiD framework - coefficients of interactions of same-sex and year dummies

a. Depression

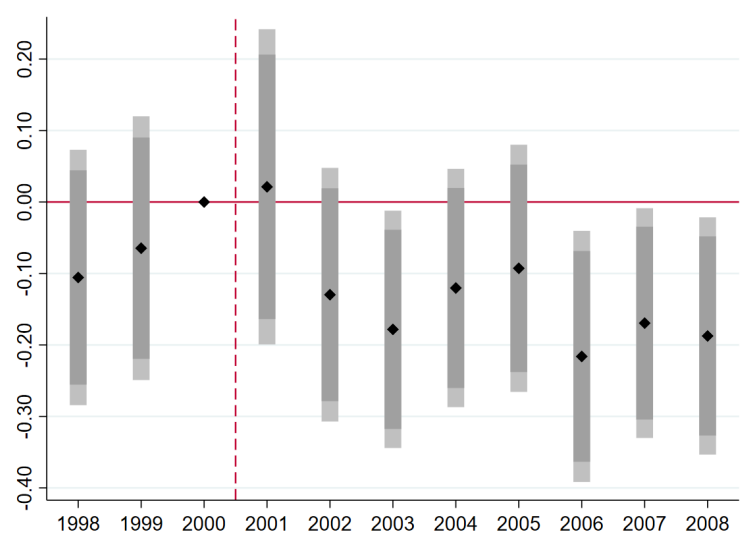

b. Anxiety

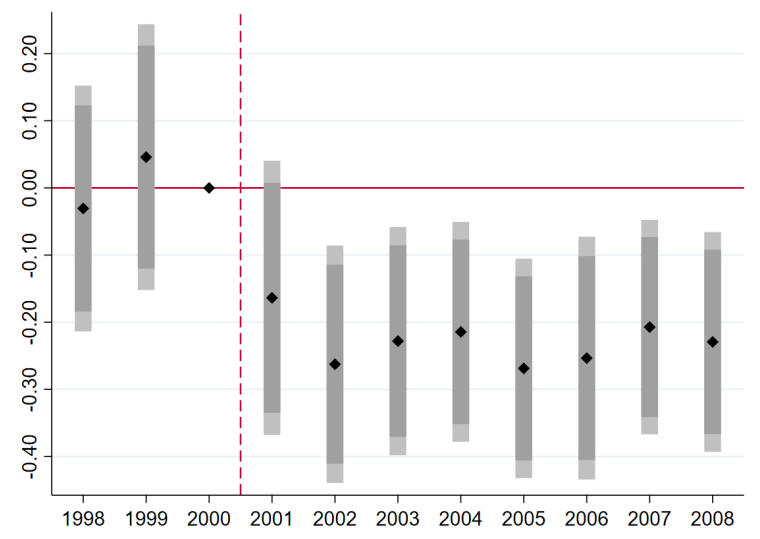

Note: The coefficient of same-sex $\times$ the period 2000 to 2001 pre-law is normalized to be zero for identification. The segments denote 90\% (dark) and 95\% (light) confidence intervals of estimated coefficients, respectively.

minorities and heterosexuals are parallel for our mental health indicators. Moreover, in Section 5.4 we follow Wolfers (2006) and perform a sensitivity analysis by including sexual orientation-specific time trends "to identify preexisting trends." By this means we alleviate, if not completely resolve, the potential threat of divergent pre-trends to our identification.

\section{$5 \quad$ Estimation Results}

\subsection{Baseline Parameter Estimates}

Table 4 provides our main parameter estimates. On average before SSML, sexual minorities suffered 0.177 standard deviation higher depression and 0.270 standard deviation higher anxiety. Both differences are significant. For heterosexual individuals the legislation of SSM did not have a significant effect on the mental health variables (parameter $\gamma_{2}$ ). This result verifies the assumption of our DiD approach: the natural experiment did not affect the control group. Both depression and anxiety of sexual minorities largely converged to their counterpart of heterosexuals after SSML. The legalization reduced the sexual orientation gaps of depression and anxiety by $50 \%$ (0.089/0.177) and 87\%, respectively. The last row of the table presents p-values indicating whether or not the sum of the parameters $\gamma_{1}$ and $\gamma_{3}$ equals zero. If so, it implies that SSML closed the sexual orientation gap of mental health. Despite the remarkable convergence, the sexual orientation 
gap was not yet completely eliminated even though such gap of anxiety post-SSML was significant only at the $10 \%$ level.

Table 4: Baseline parameter estimates effects of same-sex marriage legalization on mental health

\begin{tabular}{lrlll}
\hline & \multicolumn{2}{c}{ Depression } & \multicolumn{2}{c}{ Anxiety } \\
\hline Same-sex $\left(\gamma_{1}\right)$ & 0.177 & $(0.039)^{* * *}$ & 0.270 & $(0.041)^{* * *}$ \\
SSML $\left(\gamma_{2}\right)$ & -0.006 & $(0.044)$ & 0.068 & $(0.044)$ \\
Same-sex $\times$ SSML $\left(\gamma_{3}\right)$ & -0.089 & $(0.044)^{* *}$ & -0.235 & $(0.045)^{* * *}$ \\
\hline$p$ value $\left(\gamma_{1}+\gamma_{3}=0\right)$ & \multicolumn{2}{c}{$0.0001^{* * *}$} & \multicolumn{2}{c}{$0.094^{*}$} \\
\hline
\end{tabular}

Note: Based on 40,586 observations. Only the relevant parameter estimates are presented. Appendix B1 displays estimates of all parameters; ${ }^{*} \mathrm{p}<0.10 ;{ }^{* *} \mathrm{p}<0.05 ; * * * \mathrm{p}<0.01$. Robust standard errors in parentheses.

Estimates of covariates are reported in Table 8 in Appendix B1. Females suffered 0.165 standard deviation higher depression and 0.312 standard deviation higher anxiety. Age exerts statistically significant influence on both mental health indicators too. Based on the quadratic specification of age effects, the mental health conditions present an inverted "U" shape along age with the vertex at 45 year-old for depression and 51 for anxiety. Compared to never married individuals, on average marrieds had more satisfactory mental health status in both indicators. The divorced and widowed suffered more serious mental health issues. Non-Dutch citizens in the Netherlands had worse mental health conditions than Dutch citizens but the difference was not significant for anxiety. Employees enjoyed better expected mental health than non-employees. Moreover, individuals with a higher educational attainment had a better mental health status for depression but not for anxiety; people residing in a place with a higher urban degree suffered more serious mental health problems.

Furthermore, the calendar year fixed effects account for both the evolution of mental health indicators across time and the changes in measurement common for all people. Indeed for our mental health measures, the coefficients of most post-2000 years are in an opposite direction to the phase before 2001 suggesting that the calendar year effects are mainly driven by the measurement changes of mental health that occurred in 2001 . Finally, the constant represents the expected mental health conditions of the general reference group, i.e. never married heterosexual Dutch men who are non-employed without a high school degree, live in the countryside and answered the health survey in January, 1998. Among this group of people, they had an anxiety score of -0.625 and an insignificant depression score of -0.039 . 


\subsection{Potential Mechanisms}

In this subsection, we explore the mechanisms through which SSML may have affected mental health. After the legislation, sexual minority couples are allowed to get married to a same-sex spouse and thus enjoy the well-being and health gains from marriage. The legalization may also stabilize the partnership market reducing separation rates (Chen and van Ours, 2020), which facilitates the improvement in mental health (Strohschein et al., 2005; Kohn and Averett, 2014). Moreover, even for sexual minorities who did not take the option of marriage soon after SSML, the enlarged choice set of future partnership forms granted to them may benefit their mental health as well as encourage their formal partnership formation in the future. After all, more options do not hurt. In addition, the improvement in societal attitudes toward sexual minorities (Aksoy et al., 2020) or self-perception of being societally accepted (Badgett, 2011) owing to SSML may help to shrink the sexual orientation gap in mental health. We analyze and discuss these channels below.

First, to examine the potential mechanism of marriage, we replace in Equation (1) Same-sex $\times S S M L$ by Same-sex $\times S S M L \times$ Married and Same-se $\times$ SSML $\times$ Nonmarried. Here Married does not include RP, so the coefficient of Same-sex $\times S S M L \times$ Married captures the impact of entering an official SSM permitted in the post-SSML phase only. Non-married $=1-$ Married, thus Same-sex $\times S S M L \times$ Non-married identifies the impact of non-married status for sexual minorities post-legalization. Estimates are reported in Table 5.

Table 5: Parameter estimates potential mechanism of marriage

\begin{tabular}{lcccc}
\hline & \multicolumn{2}{c}{ Depression } & \multicolumn{2}{c}{ Anxiety } \\
\hline Same-sex $\left(\gamma_{1}\right)$ & 0.227 & $(0.038)^{* * *}$ & 0.304 & $(0.040)^{* * *}$ \\
$\mathrm{SS} \times \mathrm{SSML} \times$ Married $\left(\gamma_{4}\right)$ & -0.181 & $(0.061)^{* * *}$ & -0.187 & $(0.063)^{* * *}$ \\
$\mathrm{SS} \times \mathrm{SSML} \times$ Non-married $\left(\gamma_{5}\right)$ & -0.088 & $(0.045)^{*}$ & -0.257 & $(0.045)^{* * *}$ \\
\hline$p$ value $\left(\gamma_{4}=\gamma_{5}\right)$ & $0.073^{*}$ & 0.178 & \\
$p$ value $\left(\gamma_{1}+\gamma_{4}=0\right)$ & 0.330 & $0.016^{* *}$ \\
$p$ value $\left(\gamma_{1}+\gamma_{5}=0\right)$ & $0.000^{* * *}$ & \multicolumn{2}{c}{$0.036^{* *}$} \\
\hline
\end{tabular}

Note: Based on 40,586 observations; see also footnote Table 4.

The coefficients of Same-sex $\times S S M L \times$ Married indicate that officially married sexual minorities acquired substantially larger improvements in depression than their non-married counterpart after the legislation. This difference is in the opposite direction for anxiety. In the lower panel of the table we test three hypotheses: (1) whether SSML affected married and non-married sexual minorities differently; (2) whether mental health of married sexual minorities completed convergence to heterosexuals; and (3) 
whether mental health of non-married sexual minorities completed convergence to heterosexuals. The p-values for the first test suggest significant divergences between married and non-married sexual minorities for depression but insignificant differentials for anxiety at the 10\% level. Results of the second and third tests tell that SSML closed the sexual orientation gap in depression for married sexual minorities but did not completely close the gap in anxiety or for non-married sexual minorities. Thus marriage itself seemed to play a beneficial role in reducing depression among sexual minorities following SSML.

Note that we are not trying to identify the causal effect of marriage protection on mental health. With our cross-sectional data set we are unable to account for potential selection into marriage or reverse causality (see Chen and van Ours (2018) for a detailed discussion on these issues). Here we simply explore the role of marriage by comparing the differential effects of SSML between married and non-married sexual minorities. The significant mental health improvement among non-married sexual minorities after SSML should be interpreted beyond marriage itself.

Second, if SSML did not improve both mental health indicators of sexual minorities through marriage only, the legalization could exert its influence by stabilizing same-sex relationships and diminishing their separation rates. A large literature has documented a negative association between (mental) health and separations, e.g. Strohschein et al. (2005) and Kohn and Averett (2014). In panel b of Table 3 we present proportions of individuals divorced from a formal partnership by sexual orientation and pre-/post-SSML. The increase in the separation percentage for heterosexuals (1.6 percentage points) represents the general evolution of divorce as time while the $\mathrm{DiD}$ in the separation percentage in the last column means the unconditional decline in divorce of same-sex formal partnerships owing to SSML. ${ }^{12}$ Moreover, applying a bivariate timing-of-events model to the Dutch administrative data on durations of same-sex formal partnerships, Chen and van Ours (2020) show that SSML indeed stabilized the partnership market. Hence marital stability may be a mechanism.

Third, in Table 5 we see that sexual minorities who were not married also obtained mental health gains after SSML. Another possible explanation for such gains is that they enjoyed having a richer choice basket of partnership forms so that they were able to enter

\footnotetext{
${ }^{12}$ The unconditional percentage of separations within sexual minorities did not diminish substantially post-SSML in absolute terms. Nevertheless, we are trying to explain the channel for the mental health effects of SSML identified with DiD and hence in relative terms (comparing sexual minorities to heterosexuals). Therefore, we need to focus on the relative reduction in the separation percentage accounting for the calendar time related developments rather than the absolute separation change within sexual minorities.
} 
either partnership form they preferred in the future. If this is true, we should observe an increase in same-sex partnership formations post-legalization. Panel b of Table 3 also displays the proportions of individuals in a formal partnership by sexual orientation and pre-/post-SSML. The percentage of formally partnered sexual minorities rose after the legislation by 5.1 percentage points, and with heterosexuals as the benchmark by 8.1 percentage points. Furthermore, this channel of an enlarged choice set again goes along with Carpenter et al. (2018) and Chen and van Ours (2020) who find that the legalization induced not only never married sexual minorities crowding into marriage (both studies) but also same-sex registered partnerships transforming into marriage (the latter study). Thus such richer choice basket of partnership forms may contribute to the mental health gains especially for those non-married sexual minorities.

Finally, indirect channels, such as improvement in societal attitudes toward sexual minorities or self-perception of being socially accepted may also play an important role in alleviating sexual minorities' mental health issues. Aksoy et al. (2020) adopt annual attitudes toward sexual minorities from the European Social Survey (ESS) and find that these attitudes improved following the laws recognizing same-sex relationships. ${ }^{13}$ Badgett (2011) concludes on the basis of an analysis of qualitative data from the Netherlands and Massachusetts that the right to marry and exercising the right to marry are associated with greater feelings of social inclusion among same-sex couples. This evidence implies that SSML has worked well as an anti-discrimination policy with beneficial spillover effects to the mental health of sexual minorities.

\subsection{Heterogeneity Investigation}

The effects of SSML may not be homogeneous across the board. The mental health of some specific sub-groups in sexual minorities may be especially impacted by the legalization. We investigate the heterogeneous effects in terms of gender, urbanization of respondents' residence, age, employment status and educational attainment. This exploration may help us to understand how the improvement in societal attitudes to sexual minorities owing to the legislation exerted influence on their mental health. For parsimony Table 6 shows the most interesting coefficients only, i.e. those of Same-sex $\times S S M L$,

\footnotetext{
${ }^{13}$ Unfortunately the ESS began in 2002 thus we could not obtain a pre-SSML wave for the Netherlands to compare. Though we cannot directly relate it to SSML, the Eurobarometer indeed presents improved attitudes of Dutch respondents toward sexual minorities after the legislation. In the wave of 1997 preSSML, the proportions of being in favor of the right of sexual minorities to get married and to adopt children were $85.3 \%$ and $70.3 \%$, respectively. In 2001 post-SSML, these percentages increased to $90.0 \%$ and $74.3 \%$, respectively.
} 
where in panel a the baseline estimates are reproduced for ease of comparison. The downside of splitting up our sample in various dimensions is the reduction in the number of observations and thus the decline in statistical significance.

Table 6: Parameter estimates effects of same-sex marriage legalization on mental health; heterogeneity by subgroups

\begin{tabular}{lrlrlr}
\hline & \multicolumn{2}{c}{ Depression } & \multicolumn{2}{c}{ Anxiety } & No. obs \\
\hline a. Baseline & -0.089 & $(0.044)^{* *}$ & -0.235 & $(0.045)^{* * *}$ & 40,586 \\
\hline b. Gender & & & & & \\
Men & -0.061 & $(0.058)$ & -0.194 & $(0.056)^{* * *}$ & 19,069 \\
Women & -0.166 & $(0.066)^{* *}$ & -0.282 & $(0.072)^{* * *}$ & 21,517 \\
\hline c. Degree of ubanization & & & & & \\
Low & -0.146 & $(0.066)^{* *}$ & -0.244 & $(0.069)^{* * *}$ & 24,857 \\
High & -0.048 & $(0.059)$ & -0.231 & $(0.060)^{* * *}$ & 15,729 \\
\hline d. Age & & & & & \\
Young (16-30) & -0.129 & $(0.057)^{* *}$ & -0.171 & $(0.059)^{* * *}$ & 11,454 \\
Middle aged (31-55) & 0.024 & $(0.071)$ & -0.114 & $(0.071)$ & 29,132 \\
Older (56-90) & -0.049 & $(0.148)$ & -0.017 & $(0.135)$ & 16,109 \\
Extended sample (16-90) & -0.128 & $(0.042)^{* * *}$ & -0.256 & $(0.042)^{* * *}$ & 56,695 \\
\hline e. Labor market status & & & & & \\
Employed & -0.088 & $(0.047)^{*}$ & -0.231 & $(0.048)^{* * *}$ & 33,589 \\
Non-employed & -0.135 & $(0.108)$ & -0.281 & $(0.112)^{* *}$ & 6,997 \\
\hline f. Educational attainment & & & & & \\
No college degree & -0.050 & $(0.081)$ & -0.217 & $(0.077)^{* * *}$ & 13,420 \\
College degree & -0.098 & $(0.052)^{*}$ & -0.238 & $(0.055)^{* * *}$ & 27,166 \\
\hline
\end{tabular}

Note: Only parameter estimates of Same-sex $\times$ SSML are presented in the table for parsimony and the ease of comparison; see also footnote Table 4 .

Panel b of Table 6 displays the estimates separately by gender. Although there are differences in magnitude or significance, the results are qualitatively similar to the baseline in panel a. Gay men and lesbian women suffered more serious mental health issues than their corresponding heterosexual counterparts (i.e. the coefficients of Same-sex which are not reported in the table but available upon request). The SSML effects are more significant both statistically and economically for lesbian women than gay men. Even for the insignificant effects, the point estimates are in the same direction as for the pooled estimates. Post-SSML, both mental health indicators of lesbian women significantly approached those of heterosexual women. The same holds among men for anxiety.

Usually big cities have a more friendly environment to sexual minorities. Since people in urban regions had been already more tolerant to sexual minorities pre-SSML, this legislation might not further improve the attitudes to them in urban areas as much as in non-urban regions. However, it could also be that tolerant cities positively responded to a larger extent to the legalization than the conservative countryside. Therefore, the improvements in attitudes and thus in mental health of sexual minorities could be either 
bigger or smaller in urban regions than in non-urban ones. Panel c of Table 6 presents estimates in less urban areas and highly urban regions, respectively. As expected, thanks to the more tolerant environment in cities, sexual minorities suffered less serious mental health issues relative to heterosexuals in highly urban areas than in less urban regions (i.e. the coefficients of Same-sex not reported here). The legalization of SSM significantly diminished depression and anxiety in a larger scale for sexual minorities in low urban areas than in higher urban ones. Thus the results seem more inclined to support the first hypothesis: SSML benefited mental health of sexual minorities more in rural areas than in highly urban places where the vibe had been already more friendly to sexual minorities pre-legalization.

Panel d of Table 6 distinguishes individuals among three age cohorts: the young (16 to 30 years old), the middle aged (31 to 55 years old), and the older (56 to 90 years old). Generally speaking, in the pre-SSML period the sexual orientation gaps of mental health were significant and larger among people younger than 56 (i.e. the coefficients of Same-sex). The legalization also benefited mental health of younger sexual minorities more than older ones. Moreover, we conduct a sensitivity analysis with an extended age sample in the last row of panel $\mathrm{d}$. This sample includes individuals older than 55 who were excluded in the baseline analysis. The estimated sexual orientation gaps in mental health pre-SSML (i.e. the coefficients of Same-sex not reported here) are similar to the baseline ones but the estimated effects of SSML for sexual minorities are stronger and more significant.

The differences between the employed and the non-employed are presented in panel e of Table 6. Non-employment could mean unemployment or not being in the labor force because of either still receiving education or quitting the labor force. The sexual orientation gaps of mental health before SSML were bigger among non-employed people than among employed ones (i.e. the coefficients of Same-sex not reported here). Such gaps were reduced by SSML also more substantially among the non-employed though the effect on depression is insignificant.

Finally, in panel f of Table 6 we show divergent mental health effects of SSML between college degree holders and individuals without a college degree. The college here refers to either applied college or research university. The sexual orientation gaps of depression and anxiety pre-SSML were larger for people without a college degree. Furthermore, the sexual orientation gaps of mental health were closed by the legislation more completely relative to their initial levels among college degree holders.

All in all, after examining a variety of heterogeneities, we find that SSML diminished 
the sexual orientation gaps of mental health more successfully among women, residents in low urban regions, younger people and college degree holders. It could be because communities surrounding these groups reacted more positively to the legislation by improving their attitudes to sexual minorities, or because these groups responded more actively to the legalization perceiving themselves as more accepted by society.

\subsection{Sensitivity Analyses}

We perform a sensitivity analysis by adding to our model sexual orientation-specific time trends which are capable to capture potential divergent preexisting trends. We then implement additional analyses with an extended estimation sample including individuals with unidentified sexual orientation and with alternative measures for depression and anxiety. We also conduct falsification tests by exploiting different timings pre-SSML as fake marital policy changes. We show that our results are robust to variations in these dimensions.

\subsubsection{Inclusion of Sexual Orientation-Specific Time Trends}

Wolfers (2006) argues that a model may be misspecified by assuming an immediate constant response to a policy shock and that including group-specific time trends might exacerbate the resulting bias if the pre-shock period is considerably shorter than the post-shock one. He thus suggests to include dummy variables for the first two years of the new policy phase, for year three and four, five and six, etc. in addition to the groupspecific time trends. In this way these time trends will be able to identify preexisting trends.

Adopting his idea, we establish the same model specification allowing for flexible response dynamics to the legislation and including sexual orientation-specific linear time trends. Panel b of Table 7 displays the relevant estimates. After including the sexual orientation-specific time trends, the beneficial effect of SSML on depression escalated over time but it is not precisely estimated. The effect on anxiety is close to the baseline and rather stable across years. Though significant only in the first two years following the legalization, the separate point estimates over time are virtually identical to one another.

\subsubsection{Inclusion of Individuals with Unidentified Sexual Orientation}

Previously we excluded individuals whose sexual orientation cannot be identified. They did not form any (reported) cohabitation, registered partnership or marriage during the 
whole period of the administrative data. They could be the young who had not established their first relationship or those that had been divorced or widowed since 1995 .

It is difficult to decide whether to categorize these unidentified people as heterosexuals or sexual minorities. We first provisionally regard them as heterosexuals simply because with respect to the mental health indicators they are more similar to heterosexuals. The first row in panel c of Table 7 reports estimates corresponding to such classification. They are virtually identical to the baseline estimates in both the magnitude and the significance.

Nonetheless, it could be also the case that these unidentified individuals were sexual minorities and that they did not want to come out of the closet so they chose not to report any relationship with a same-sex partner. A caveat relevant to this speculation is that the proportion of sexual minorities would increase to $17 \%$ which is substantially higher than that in other studies using representative Dutch surveys, e.g. Buser et al. (2018) and Chen and van Ours (2018). Still, we show in the second row of panel c estimates based on such categorization. The effects of SSML are qualitatively consistent with those in the baseline specification though the effect on depression loses the significance and the one on anxiety declines considerably.

Table 7: Sensitivity analysis - parameter estimates effect of SSML on mental health

\begin{tabular}{|c|c|c|c|c|c|}
\hline & \multicolumn{2}{|c|}{ Depression } & \multicolumn{2}{|c|}{ Anxiety } & \multirow{2}{*}{$\begin{array}{r}\text { No. obs } \\
40,586\end{array}$} \\
\hline a. Baseline & -0.089 & $(0.044)^{* *}$ & -0.235 & $(0.045)^{* * *}$ & \\
\hline \multicolumn{6}{|l|}{ b. Group spec. trends } \\
\hline Same-sex $\times$ Year 2001 post- 2 & -0.030 & $(0.103)$ & -0.222 & $(0.097)^{* *}$ & \multirow{4}{*}{40,586} \\
\hline Same-sex×Year 2003-4 & -0.118 & $(0.145)$ & -0.214 & $(0.140)$ & \\
\hline Same-sex $\times$ Year $2005-6$ & -0.119 & $(0.202)$ & -0.251 & $(0.190)$ & \\
\hline Same-sex $\times$ Year 2007-8 & -0.170 & $(0.2$ & -0.200 & $(0.247)$ & \\
\hline \multicolumn{6}{|c|}{ c. Unknown sexual orientation } \\
\hline Regarded as hetero. & -0.089 & $(0.043)^{* *}$ & -0.231 & $(0.045)^{* * *}$ & 43,747 \\
\hline Regarded as sex. mino. & -0.030 & $(0.032)$ & -0.133 & $(0.033)^{*}$ & 43,747 \\
\hline \multicolumn{6}{|l|}{ d. Placebo timing } \\
\hline 2001 pre-SSML & 0.074 & $(0.183)$ & -0.003 & $(0.148)$ & 12,288 \\
\hline 2000 & 0.090 & $(0.079)$ & -0.002 & $(0.083)$ & 12,288 \\
\hline 1999 & 0.063 & $(0.079)$ & 0.055 & $(0.082)$ & 12,288 \\
\hline e. Prevalence measures & -0.037 & $(0.019)^{*}$ & -0.091 & $(0.109)^{* * *}$ & 40,586 \\
\hline
\end{tabular}

\subsubsection{Placebo Tests of SSML Timings}

To establish a relationship between SSML and mental health, there must not have been other events responsible for the divergence between sexual minorities and heterosexuals occurring at a time close to the legalization. Placebo tests applying fake reform timings 
in the pre-SSML period will provide such evidence if we do not find similar effects of the fake policy change to that of the real legislation. We use the pre-SSML sample to conduct such tests whose results are displayed in panel $\mathrm{d}$ of Table $7 .{ }^{14}$

We change the onset of the fake policy reform to the beginning of 2001 in the first row of panel d, to the beginning of 2000 in the second row and of 1999 in the third row. The fake policy change did not exert a significant influence on the mental health of sexual minorities.

\subsubsection{Prevalence Measures}

In the main analysis, the standardized measures of depression and anxiety represent the intensity of mental illnesses. Panel e of Table 7 reports estimates with binary measures of depression and anxiety (see details in Appendix A1). The binary measures indicate the prevalence, i.e. the proportion in the population who suffers from depression and anxiety, respectively.

Qualitatively similar to the baseline results, prevalence of depression diminished by 3.7 percentage points while prevalence of anxiety declined by 9.1 percentage points among sexual minorities after SSML. Thus we obtain the same conclusions no matter whether we use intensity measures or prevalence indicators.

With additional robustness checks by including sexual orientation-specific time trends and allowing for flexible response dynamics to SSML, using a comprehensive sample including individuals with unknown sexual orientation, or exploiting prevalence mental health measures rather than intensity ones, we draw the same conclusions as from the baseline analysis. Furthermore, we exclude the possibility of confounding events responsible for the improved mental health among sexual minorities. These results confirm the mental health gains of SSML for sexual minorities.

\section{Conclusions}

For a long time, sexual minorities have been discriminated in different situations including the right of formal marriage. Such discrimination and unfair treatment may have harmed their mental health. Over the past couple of decades, in more and more countries marriage

\footnotetext{
${ }^{14}$ One might include the post-SSML sample for such falsification test if one is interested in how the impact of SSML, if there was, would materialize in the post-SSML phase, i.e. immediately or gradually. Such curiosity has been fed in panel b of Table 7 and again in Figure 4.
} 
has been made available to same-sex couples. This reform of marital policy may have exerted beneficial mental health effects for sexual minorities.

We study how the 2001 same-sex marriage legalization in the Netherlands affected mental health of sexual minorities focusing on depression and anxiety. The societal attitudes towards homosexuality in the Netherlands are highly tolerant. In such an open-minded society one would expect the effects of SSML on mental health of sexual minorities to be limited. We find that marriage itself was only partially responsible for the amelioration of mental health among sexual minorities. In the post-legislation period married sexual minorities enjoyed significantly larger improvement than non-married ones for depression but not for anxiety. More importantly, the legal recognition of same-sex marriage improved mental health for both male and female sexual minorities irrespective of their own marital status.

SSML largely closed the mental health gap between sexual minorities and heterosexual individuals in the Netherlands. As a typical anti-discrimination policy, SSML is effective in improving not only societal attitudes to discriminated individuals (sexual minorities in the current context) but also their health and well-being. The findings of the current study suggest that anti-discrimination policies may have beneficial mental health effects also on other discriminated minorities with respect to race, religion, immigration, disability and so forth.

The high tolerance and open mind for sexual minorities in the Netherlands may generate a concern on the external validity of our study. In less tolerant or more conservative countries and areas, the effects of SSML could be different. Nonetheless, in that case there is more room for the improvement of societal attitudes to sexual minorities. Therefore, the mental health effects of SSML in the Netherlands are likely to be a lower bound for less tolerant or more conservative societies. 


\section{References}

Ahmed, A., L. Andersson, and M. Hammarstedt (2013). Are homosexuals discriminated against in the hiring process? Southern Economic Journal 79(3), 565-585.

Aksoy, C. G., C. S. Carpenter, R. De Haas, and K. Tran (2020). Do laws shape attitudes? Evidence from same-sex relationship recognition policies in Europe. European Economic Review 124, 103399.

Atanasov, V. and B. Black (2016). Shock-based causal inference in corporate finance and accounting research. Critical Finance Review 5, 207-304.

Autor, D. H. (2003). Outsourcing at will: The contribution of unjust dismissal doctrine to the growth of employment outsourcing. Journal of Labor Economics 21(1), 1-42.

Badgett, M. L. (2011). Social inclusion and the value of marriage equality in Massachusetts and the Netherlands. Journal of Social Issues 67(2), 316-334.

Badgett, M. L., C. S. Carpenter, and D. Sanson (2020). LGBTQ Economics. mimeo.

Baker, M., Y. Halberstam, K. Kroft, A. Mas, and D. Messacar (2019). Pay transparency and the gender gap. NBER Working Paper No. 25834.

Baranov, V., R. De Haas, and P. Grosjean (2020). Queens of the desert: Convictism and marital attitudes across Australia. AEA Papers and Proceedings 110, 457-462.

Behaghel, L., B. Crépon, and T. Le Barbanchon (2015). Unintended effects of anonymous résumés. American Economic Journal: Applied Economics 7(3), 1-27.

Bennedsen, M., E. Simintzi, M. Tsoutsoura, and D. Wolfenzon (2020). Do firms respond to gender pay gap transparency? NBER Working Paper No. 25435.

Bertrand, M. and E. Duflo (2017). Field experiments on discrimination. In A. V. Banerjee and E. Duflo (Eds.), Handbook of Field Experiments, Volume 1, pp. 309 - 393. North-Holland.

Boeri, T. and J. C. van Ours (2013). The Economics of Imperfect Labor Markets. Princeton: Princeton University Press.

Buser, T., L. Geijtenbeek, and E. Plug (2018). Sexual orientation, competitiveness and income. Journal of Economic Behavior $\& 3$ Organization 151, 191-198.

Carpenter, C., S. T. Eppink, G. Gonzales Jr, and T. McKay (2018). Effects of access to legal same-sex marriage on marriage and health: Evidence from BRFSS. NBER Working Paper No. 24651.

Chen, S. and J. C. van Ours (2018). Subjective well-being and partnership dynamics: Are same-sex relationships different? Demography 55(6), 2299-2320.

Chen, S. and J. C. van Ours (2020). Symbolism matters: The effect of same-sex marriage legalization on partnership stability. Journal of Economic Behavior \& Organization 178, $44-58$. 
Ciscato, E., A. Galichon, and M. Goussé (2020). Like attract like? A structural comparison of homogamy across same-sex and different-sex households. Journal of Political Economy 128(2), 740-781.

Coffman, K. B., L. C. Coffman, and K. M. M. Ericson (2017). The size of the LGBT population and the magnitude of antigay sentiment are substantially underestimated. Management Science 63(10), 3168-3186.

Dee, T. S. (2008). Forsaking all others? The effects of same-sex partnership laws on risky sex. The Economic Journal 118(530), 1055-1078.

Delhommer, S. and D. S. Hamermesh (2020). Same-sex couples and the marital surplus: The importance of the legal environment. Journal of Policy Analysis and Management, forthcoming.

Francis, A. M. and H. M. Mialon (2010). Tolerance and HIV. Journal of Health Economics 29(2), 250-267.

GBD 2017 Disease and Injury Incidence and Prevalence Collaborators (2018). Global, regional, and national incidence, prevalence, and years lived with disability for 354 diseases and injuries for 195 countries and territories, 19902017: a systematic analysis for the global burden of disease study 2017. The Lancet 392(10159), 1789 - 1858.

Goldin, C. and C. Rouse (2000). Orchestrating impartiality: The impact of "blind" auditions on female musicians. American Economic Review 90(4), 715-741.

Hatzenbuehler, M. L., K. A. McLaughlin, K. M. Keyes, and D. S. Hasin (2010). The impact of institutional discrimination on psychiatric disorders in lesbian, gay, and bisexual populations: A prospective study. American Journal of Public Health 100(3), 452-459.

Hatzenbuehler, M. L., C. O'Cleirigh, C. Grasso, K. Mayer, S. Safren, and J. Bradford (2012). Effect of same-sex marriage laws on health care use and expenditures in sexual minority men: A quasi-natural experiment. American Journal of Public Health 102(2), 285-291.

Holzer, H. and D. Neumark (2000). Assessing affirmative action. Journal of Economic Literature $38(3), 483-568$.

Kohn, J. L. and S. L. Averett (2014). The effect of relationship status on health with dynamic health and persistent relationships. Journal of Health Economics 36, 69-83.

Kuyper, L., J. Iedema, and S. Keuzenkamp (2013). Towards Tolerance; Exploring Changes and Explaining Differences in Attitudes towards Homosexuality in Europe. The Hague: The Netherlands Institute for Social Research (SCP).

Neumark, D. (2018). Experimental research on labor market discrimination. Journal of Economic Literature 56(3), 799-866.

Plug, E., D. Webbink, and N. Martin (2014). Sexual orientation, prejudice, and segregation. Journal of Labor Economics 32(1), 123-159.

Raifman, J., E. Moscoe, S. B. Austin, and M. McConnell (2017). Difference-in-differences analysis of the association between state same-sex marriage policies and adolescent suicide attempts. JAMA Pediatrics 171(4), 350-356. 
Ridley, M., G. Rao, F. Schilbach, and V. Patel (2020). Poverty, depression, and anxiety: Causal evidence and mechanisms. Science $370(6522)$.

Sandfort, T., R. de Graaf, M. ten Have, Y. Ransome, and P. Schnabel (2014). Same-sex sexuality and psychiatric disorders in the second Netherlands Mental Health Survey and Incidence Study (NEMESIS-2). LGBT Health 1(4), 292-301.

Sansone, D. (2019). Pink work: Same-sex marriage, employment and discrimination. Journal of Public Economics 180, 104086.

Scherf, Y. (1999). Registered Partnership in the Netherlands; A quick scan. Amsterdam: Van Dijk, Van Someren and Partners.

Stevenson, B. and J. Wolfers (2007). Marriage and divorce: Changes and their driving forces. Journal of Economic Perspectives 21(2), 27-52.

Strohschein, L., P. McDonough, G. Monette, and Q. Shao (2005). Marital transitions and mental health: Are there gender differences in the short-term effects of marital status change? Social Science E Medicine 61(11), 2293-2303.

Waaldijk, C. (2001). Small change: How the road to same-sex marriage got paved in the Netherlands. In R. Wintemute and M. Audenæs (Eds.), Legal Recognition of Same-Sex Partnerships; A Study of National, European and International Law, pp. 437-464. Oxford and Portland: Hart Publishing.

Wight, R. G., A. J. LeBlanc, and M. Lee Badgett (2013). Same-sex legal marriage and psychological well-being: Findings from the California Health Interview Survey. American Journal of Public Health 103(2), 339-346.

Wolfers, J. (2006). Did unilateral divorce laws raise divorce rates? A reconciliation and new results. American Economic Review 96(5), 1802-1820. 


\section{Appendix A: Details on Our Data}

\section{A1. Survey Questions}

In 2001 part of questions in the POLS-survey changed, which makes it not easy to directly compare the information up to year 2001 to that from 2001 onward. Here is how we handled this.

\section{Mental Health Variables}

- Prevalence of depression

1. Up to 2001: "In the past weeks did you feel depressed?" The answers are categorized into "(1) not at all, (2) sometimes, (3) often, and (4) very often". Prevalence of depression is a dummy variable with value 0 if the answer is (1) and a value of 1 otherwise

2. From 2001: "In the past 4 weeks did you feel so down in the dumps that nothing could cheer you up?" The answers are "(1) never, (2) rarely, (3) sometimes, (4) often, (5) usually, and (6) constantly. Prevalence of depression is a dummy variable with value 0 if the answer is (1) and a value of 1 otherwise.

- Depression

- The original responses are first re-scaled to the range $[0,1]$ and then standardized to have a mean of zero and a standard deviation of one for the pre-2001 period and for the phase including and after 2001, respectively. Depression is a variable combining the standardized responses of the two periods.

- Prevalence of anxiety

1. Up to 2001: "In the past weeks did you feel upset?" The answers are classified into "(1) not at all, (2) sometimes, (3) often, and (4) very often". Prevalence of anxiety is a dummy variable with value 0 if the answer is (1) and value 1 otherwise.

2. From 2001: "For at least two weeks did you feel anxious or worried?" The answers are "(1) yes, and (2) no". Prevalence of anxiety is a dummy variable with value 0 if the answer is (2) and value 1 otherwise.

- Anxiety

- The original responses are first re-scaled to the range $[0,1]$ and then standardized to have a mean of zero and a standard deviation of one for the pre-2001 period and for the phase including and after 2001, respectively. Anxiety is a variable combining the standardized responses of the two periods. 


\section{Other Health Related Variables}

- Feeling nervous

1. Up to 2001: "In the past weeks did you feel restless ?" The answers are "(1) not at all, (2) sometimes, (3) often, and (4) very often".

2. From 2001: "In the past 4 weeks did you feel very nervous?" The answers are"(1) never, (2) rarely, (3) sometimes, (4) often, (5) usually, and (6) constantly".

The original responses are first re-scaled to the range $[0,1]$ and then standardized to have a mean of zero and a standard deviation of one for the pre-2001 period and for the phase including and after 2001, respectively. Feeling nervous is a variable combining the standardized responses of the two periods.

- Bad general health

This variable is asked consistently over time: "What do you think of the general state of your health?" The answers changed in 2001

1. Up to 2001: "(1) very good, (2) good, (3) okay, (4) sometimes good and sometimes bad, (5) bad";

2. From 2001: "(1) excellent, (2) very good, (3) good, (4) mediocre, (5) bad".

The original responses are first re-scaled to the range $[0,1]$ and then standardized to have a mean of zero and a standard deviation of one for the pre-2001 period and for the phase including and after 2001, respectively. Bad general health is a variable combining the standardized responses of the two periods.

- Sleeping pills

There are two questions about use of sleeping pills: one is on prescription and the other is not, both with answers of "(1) yes, and (2) no". Sleeping pills is a dummy variable with value 0 if the answer is (2) to both questions and value 1 otherwise.

\section{- Feeling empty}

This variable is asked consistently over time: "Do you feel empty at the end of the working day?" The answers are categorized into "(1) never, (2) several times a year, (3) monthly, (4) a few times a month, (5) every week, (6) a few times a week, and (7) everyday". Feeling empty is a variable with the original response categories.

- Heavy drinking

This variable is asked consistently over time: "Do you drink more than 6 glasses of alcohol at least one day per week?" The answers are categorized into "(1) yes, and (2) no". Heavy drinking is a dummy variable with value 0 if the answer is (2) and value 1 otherwise.

- Drinking 
1. Up to 2001: "Do you use alcoholic drinks?" The answers are classified into "(1) yes, and (2) no". Drinking is a dummy variable with value 0 if the answer is (2) and value 1 otherwise.

2. From 2001: Two relevant questions "Do you sometimes drink alcohol on weekdays?" and "Do you sometimes drink alcohol on weekend?" The answers are "(1) yes, and (2) no" to both questions. Drinking is a dummy variable with value 0 if the answer is (2) to both questions and value 1 otherwise.

\section{- Smoking}

This variable is asked consistently over time: "Do you smoke?" The answers changed in 2001

1. Up to 2001: "(1) yes, and (2) no". Smoking is a dummy variable with value 0 if the answer is (2) and value 1 otherwise.

2. From 2001: "(1) smoke, (2) smoke sometimes, and (3) do not smoke". Smoking is a dummy variable with value 0 if the answer is (3) and value 1 otherwise.

- Sexual partners

This variable is asked consistently over time: "In the past 12 months how many sexual partners did you have?" The answers are categorized as "(1) none, (2) one, (3) two, (4) three to five, (5) six or more". Sex partner is a dummy variable with value 0 if the answer is (1) and value 1 otherwise. Multiple sex partner is a dummy variable with value 0 if the answer is (1) or (2) and value 1 otherwise.

- Sexually transmitted infections

This variable is asked consistently over time: "Are you diagnosed with the following diseases: gonorrhea, syphilis, chlamydia, genital herpes, genital warts, hepatitis B?" The answers to each of these diseases are "(1) yes, and (2) no". STI is a dummy variable with value 0 if the answer is (2) to all the above mentioned diseases and value 1 otherwise. 


\section{A2. Definition of Variables}

\begin{tabular}{|c|c|}
\hline Variable & Definition \\
\hline Depression & Severity of depression; standardized score \\
\hline Prevalence of depression & Dummy variable if being depressed \\
\hline Anxiety & Severity of anxiety; standardized score \\
\hline Prevalence of anxiety & Dummy variable if being anxious \\
\hline Feeling nervous & Severity of nervous feeling; standardized score \\
\hline Bad general health & Severity of bad general health; standardized score \\
\hline Sleeping pill & Dummy variable if use of sleeping pills \\
\hline Feeling empty & Dummy variable if feeling empty at the end of the working day \\
\hline Heavy drinking & Dummy variable if consuming alcohol heavily \\
\hline Drinking & Dummy variable if drinking alcohol \\
\hline Smoking & Dummy variable if smoking \\
\hline Sex partner & Dummy variable if having sexual partner(s) in the past 12 months \\
\hline Multi sex partners & Dummy variable if having more than one sexual partners in the past 12 months \\
\hline STI & Dummy variable if diagnozed with sexually transmitted infections \\
\hline SSML & Dummy variable for the period after same-sex marriage legalization \\
\hline Heterosexual & Dummy variable if having only different-sex partnership(s) \\
\hline Same-sex & Dummy variable if having same-sex partnership(s) \\
\hline Female & Dummy variable if female \\
\hline Age & Age when surveyed \\
\hline Never married & Dummy variable if never married \\
\hline Married & Dummy variable if married or register partnered \\
\hline Divorced & Dummy variable if divorced \\
\hline Widowed & Dummy variable if widowed \\
\hline Non-Dutch & Dummy variable if not a Dutch citizen \\
\hline Employed & Dummy variable if employed \\
\hline Primary school & Dummy variable if highest completed education is primary school \\
\hline Secondary school & Dummy variable if highest completed education is secondary school \\
\hline Vocational school & Dummy variable if highest completed education is vocational school \\
\hline Applied college & Dummy variable if highest completed education is applied college \\
\hline University & Dummy variable if highest completed education is university \\
\hline Non-urban & Dummy variable if residing in a non-urban place \\
\hline Little urban & Dummy variable if residing in place with a little urban degree \\
\hline Medium urban & Dummy variable if residing in place with a medium urban degree \\
\hline Strongly urban & Dummy variable if residing in place with a strongly urban degree \\
\hline Very strongly urban & Dummy variable if residing in place with a very strongly urban degree \\
\hline
\end{tabular}




\section{A3. Descriptives}

\begin{tabular}{lccc}
\hline Variable & Different-sex & Same-sex & All \\
\hline Depression & -0.010 & 0.131 & 0.003 \\
Prevalence of depression & 0.382 & 0.425 & 0.386 \\
Anxiety & 0.026 & 0.084 & 0.032 \\
Prevalence of anxiety & 0.288 & 0.308 & 0.290 \\
Feeling nervous & -0.005 & 0.168 & 0.010 \\
Bad general health & -0.134 & -0.204 & -0.141 \\
Sleep. pill & 0.036 & 0.039 & 0.036 \\
Feeling empty & 2.424 & 2.564 & 2.436 \\
Heavy drinking & 0.133 & 0.184 & 0.138 \\
Drinking & 0.934 & 0.949 & 0.935 \\
Smoking & 0.320 & 0.385 & 0.326 \\
Sex partner & 0.953 & 0.856 & 0.946 \\
Multi sex partners & 0.034 & 0.201 & 0.046 \\
STI & 0.045 & 0.100 & 0.049 \\
SSML & 0.692 & 0.752 & 0.697 \\
Age/10 & 3.813 & 2.995 & 3.739 \\
Never married & 0.286 & 0.754 & 0.329 \\
Married & 0.655 & 0.173 & 0.611 \\
Divorced & 0.053 & 0.069 & 0.054 \\
Widowed & 0.006 & 0.004 & 0.006 \\
Non-Dutch & 0.024 & 0.043 & 0.026 \\
Employed & 0.830 & 0.800 & 0.828 \\
Primary school & 0.090 & 0.085 & 0.089 \\
Secondary school & 0.146 & 0.091 & 0.141 \\
Vocational school & 0.097 & 0.135 & 0.100 \\
Applied college & 0.416 & 0.351 & 0.410 \\
University & 0.251 & 0.339 & 0.259 \\
Non-urban & 0.170 & 0.081 & 0.162 \\
Little urban & 0.247 & 0.152 & 0.238 \\
Medium urban & 0.218 & 0.165 & 0.213 \\
Strongly urban & 0.256 & 0.309 & 0.261 \\
Very strongly urban & 0.110 & 0.292 & 0.127 \\
\hline Observations & 36,915 & 3,671 & 40,586 \\
\hline
\end{tabular}

Note: the averages of the standardized measures (Depression, Anxiety, Feeling nervous, and Bad general health) in the last column are close to but not strictly zero since the statistics shown in the above table are for the estimation sample excluding individuals older than 55 while the standardization is based on the full sample. 


\section{Appendix B}

\section{B1. Full Parameter Estimates}

In Table 8 we present the full parameter estimates related to our baseline estimates presented in Table 4.

Table 8: Baseline parameter estimates effects of same-sex marriage legalization on mental health

\begin{tabular}{|c|c|c|c|c|}
\hline & \multicolumn{2}{|c|}{ Depression } & \multicolumn{2}{|c|}{ Anxiety } \\
\hline Same-sex $\left(\gamma_{1}\right)$ & 0.177 & $(0.039)^{* * *}$ & 0.270 & $(0.041)^{* * *}$ \\
\hline $\operatorname{SSML}\left(\gamma_{2}\right)$ & -0.006 & $(0.044)$ & 0.068 & $(0.044)$ \\
\hline Same-sex $\times \operatorname{SSML}\left(\gamma_{3}\right)$ & -0.089 & $(0.044)^{* *}$ & -0.235 & $(0.045)^{* * *}$ \\
\hline Female & 0.165 & $(0.010)^{* * *}$ & 0.312 & $(0.010)^{* * *}$ \\
\hline Age/10 & 0.197 & $(0.035)^{* * *}$ & 0.276 & $(0.035)^{* * *}$ \\
\hline Age squared/100 & -0.022 & $(0.005)^{* * *}$ & -0.027 & $(0.005)^{* * *}$ \\
\hline Married & -0.113 & $(0.015)^{* * *}$ & -0.083 & $(0.015)^{* * *}$ \\
\hline Divorced & 0.270 & $(0.030)^{* * *}$ & 0.190 & $(0.028)^{* * *}$ \\
\hline Widowed & 0.195 & $(0.077)^{* *}$ & 0.115 & $(0.072)$ \\
\hline Non-Dutch & 0.150 & $(0.038)^{* * *}$ & 0.022 & $(0.034)$ \\
\hline Employed & -0.289 & $(0.016)^{* * *}$ & -0.142 & $(0.015)^{* * *}$ \\
\hline Secondary school & -0.148 & $(0.025)^{* * *}$ & -0.031 & $(0.022)$ \\
\hline Vocational school & -0.181 & $(0.026)^{* * *}$ & -0.029 & $(0.024)$ \\
\hline Applied college & -0.202 & $(0.022)^{* * *}$ & 0.010 & $(0.020)$ \\
\hline University & -0.276 & $(0.023)^{* * *}$ & -0.010 & $(0.021)$ \\
\hline Little urban & -0.003 & $(0.015)$ & 0.027 & $(0.016)^{*}$ \\
\hline Medium urban & 0.041 & $(0.015)^{* * *}$ & 0.039 & $(0.016) * *$ \\
\hline Strongly urban & 0.083 & $(0.015)^{* * *}$ & 0.079 & $(0.016) * * *$ \\
\hline Very strongly urban & 0.093 & $(0.019)^{* * *}$ & 0.064 & $(0.019)^{* * *}$ \\
\hline 1999 & 0.034 & $(0.022)$ & 0.041 & $(0.023)^{*}$ \\
\hline 2000 & 0.030 & $(0.022)$ & 0.056 & $(0.023)^{* *}$ \\
\hline 2001 & 0.023 & $(0.041)$ & 0.006 & $(0.041)$ \\
\hline 2002 & -0.020 & $(0.050)$ & -0.067 & $(0.050)$ \\
\hline 2003 & -0.038 & $(0.049)$ & -0.055 & $(0.049)$ \\
\hline 2004 & -0.001 & $(0.049)$ & -0.067 & $(0.049)$ \\
\hline 2005 & -0.012 & $(0.049)$ & -0.076 & $(0.049)$ \\
\hline 2006 & -0.072 & $(0.050)$ & -0.120 & $(0.050)^{* *}$ \\
\hline 2007 & -0.042 & $(0.049)$ & -0.143 & $(0.050)^{* * *}$ \\
\hline 2008 & -0.062 & $(0.049)$ & -0.120 & $(0.050)^{* *}$ \\
\hline February & 0.008 & $(0.023)$ & -0.040 & $(0.024)^{*}$ \\
\hline March & 0.014 & $(0.023)$ & -0.027 & $(0.023)$ \\
\hline April & 0.014 & $(0.024)$ & 0.003 & $(0.024)$ \\
\hline May & 0.013 & $(0.023)$ & -0.011 & $(0.024)$ \\
\hline June & 0.006 & $(0.024)$ & -0.011 & $(0.024)$ \\
\hline July & -0.011 & $(0.024)$ & -0.024 & $(0.025)$ \\
\hline August & -0.048 & $(0.024)^{* *}$ & -0.008 & $(0.025)$ \\
\hline September & 0.003 & $(0.024)$ & 0.016 & $(0.025)$ \\
\hline October & -0.0004 & $(0.024)$ & -0.021 & $(0.025)$ \\
\hline November & 0.009 & $(0.023)$ & -0.018 & $(0.023)$ \\
\hline December & 0.024 & $(0.025)$ & -0.031 & $(0.025)$ \\
\hline Constant & -0.039 & $(0.065)$ & -0.625 & $(0.064)^{* * *}$ \\
\hline
\end{tabular}




\section{B2. Effects of SSML on Other Health Relevant Variables}

In addition to the two most common mental health illnesses - depression and anxiety, we also examine the impacts of SSML on some other mental health related variables i.e. feeling nervous, bad general health, use of sleeping pills, feeling empty at the end of the working day, heavy drinking, drinking, smoking. The results are shown in panel a of Table 9. On average, sexual minorities suffered significantly more serious nervousness and worse general health, were significantly more likely to use sleeping pills (1.8 percentage points), to consume more than six glasses of alcohol at least one day per week i.e. heavy drinking (2.8 percentage points), to smoke (6.0 percentage points), and significantly more frequently felt empty at the end of the working day than heterosexuals.

Table 9: Parameter estimates effects of same-sex marriage legalization on other health relevant variables

\begin{tabular}{|c|c|c|c|c|c|c|c|}
\hline a. Health indicators & $\begin{array}{l}\text { Feeling } \\
\text { nervous }\end{array}$ & $\begin{array}{l}\text { Bad } \\
\text { health }\end{array}$ & $\begin{array}{l}\text { Sleeping } \\
\text { pills }\end{array}$ & $\begin{array}{l}\text { Feeling } \\
\text { empty }\end{array}$ & $\begin{array}{l}\text { Heavy } \\
\text { drinking }\end{array}$ & Drinking & Smoking \\
\hline Same-sex $\left(\gamma_{1}\right)$ & $0.152^{* * *}$ & $0.078^{* *}$ & $0.018^{* * *}$ & $0.226^{* * *}$ & $0.028^{* *}$ & 0.016 & $0.060 * * *$ \\
\hline $\operatorname{SSML}\left(\gamma_{2}\right)$ & 0.045 & -0.009 & -0.005 & -0.049 & -0.000 & 0.000 & 0.001 \\
\hline Same-sex $\times \operatorname{SSML}\left(\gamma_{3}\right)$ & $-0.072^{*}$ & -0.060 & $-0.013^{*}$ & $-0.140^{*}$ & $-0.026^{*}$ & $-0.022^{*}$ & -0.018 \\
\hline$p$ value $\left(\gamma_{1}+\gamma_{3}=0\right)$ & $0.002^{* * *}$ & 0.353 & 0.182 & $0.017^{* *}$ & 0.754 & 0.121 & $0.000^{* * *}$ \\
\hline Observations & 40,586 & 40,586 & 40,586 & 32,975 & 40,295 & 40,295 & 40,586 \\
\hline b. Sexual behavior & $\begin{array}{l}\text { Sex } \\
\text { partner }\end{array}$ & $\begin{array}{l}\text { Multi } \\
\text { sex par. }\end{array}$ & $\begin{array}{l}\text { Diagnosed } \\
\text { STI }\end{array}$ & & & & \\
\hline Same-sex $\left(\gamma_{1}\right)$ & 0.002 & $0.118^{* * *}$ & 0.038 & & & & \\
\hline $\operatorname{SSML}\left(\gamma_{2}\right)$ & 0.023 & 0.023 & -0.012 & & & & \\
\hline Same-sex $\times \operatorname{SSML}\left(\gamma_{3}\right)$ & -0.029 & -0.060 & 0.003 & & & & \\
\hline$p$ value $\left(\gamma_{1}+\gamma_{3}=0\right)$ & 0.574 & 0.240 & 0.362 & & & & \\
\hline Observations & 2,729 & 2,729 & 2,706 & & & & \\
\hline
\end{tabular}

Note: See footnote Table 4. The small numbers of observations in panel $\mathrm{b}$ are because of a large non-response and because survey questions on sexual experiences and diseases were not asked any longer since 2002 .

The legislation of same-sex marriage did not have an impact on any outcome variables for heterosexuals (the coefficients of $S S M L$ ). However, at the $10 \%$ level it significantly reduced nervousness, the use of sleeping pills, the frequency of empty feeling and the probability of (heavy) drinking for sexual minorities (the coefficients of Same-sex $\times$ $S S M L)$. The effects of SSML on general health and the probability of smoking are not significant for sexual minorities but their direction is as expected. The penultimate row of panel a shows that after the legislation, general health, the use of sleeping pills and (heavy) drinking behavior of sexual minorities completed converging to those of heterosexuals.

In terms of sexual behavior, we adopt the following dummy variables: Sex partner, 
Multiple sex partners, and Sexually transmitted infections (diagnosed STI). In panel b sexual minorities did not present a significant divergence from heterosexuals in the likelihood of having sexual intercourse in the past year or being diagnosed with a STI. Nonetheless, they were 11.8 percentage points more likely to have multiple sexual partners in the past year than their heterosexual counterpart. Moreover, post-SSML neither heterosexuals nor sexual minorities presented significant changes in their sexual behavior even though the law insignificantly decreased sexual minorities' likelihood of sexual behavior. In other words, the legislation of SSM did not render sexual minorities more active or promiscuous in their sexual life.

\section{B3. Registered Partnerships and Mental Health}

In the main analysis we ignored the mental health effects of the introduction of RP. Here, we examine whether this policy reform in 1998 affected the mental health of sexual minorities. Using the same empirical set-up as the main analysis, we compare the variations in mental health of sexual minorities from 1997 to 1998 to those of heterosexuals. Table 10 displays the parameter estimates of interest. Apparently the implementation of RP did not exert significant influence on depression or anxiety of sexual minorities.

Table 10: Parameter estimates effects of registered partnership introduction on mental health; 1997-1998

\begin{tabular}{lcccc}
\hline & \multicolumn{2}{c}{ Depression } & \multicolumn{2}{c}{ Anxiety } \\
\hline Same-sex $\left(\gamma_{1}\right)$ & 0.096 & $(0.058)^{*}$ & 0.143 & $(0.059)^{* *}$ \\
$\operatorname{RP}\left(\gamma_{2}\right)$ & 0.028 & $(0.022)$ & 0.007 & $(0.023)$ \\
Same-sex $\times \operatorname{RP}\left(\gamma_{3}\right)$ & 0.048 & $(0.085)$ & 0.012 & $(0.087)$ \\
\hline Note: Based on 8,486 observations; see also footnote Table 4.
\end{tabular}

